\title{
DA PENÍNSULA IBÉRICA À COLÔNIA BRASILEIRA: A CULTURA DO REISADO NUMA CIDADE DO SERTÃO DA BAHIA
}

\section{FROM THE IBERIAN PENINSULA TO THE BRAZILIAN COLONY: THE CULTURE OF THE KINGDOM IN A CITY OF SERTÃO DA BAHIA}

\author{
Adão Lopes Fernandes ${ }^{1}$ \\ Denise Dias de Carvalho Sousa ${ }^{2}$
}

\begin{abstract}
RESUMO: Este artigo traz os resultados de uma pesquisa realizada na Universidade do Estado da Bahia (UNEB), no Mestrado Profissional em Educação e Diversidade (MPED), no que diz respeito à presença da tradição cultural do terno de reis, de figuras e espadas nas práticas educativas dos/as professores/as do Colégio Dom Antônio de Mendonça, em Genipapo, Saúde - BA. O estudo teve como objetivo rememorar o processo histórico da manifestação do reisado, especialmente, o terno de reis de figuras e espadas do povoado de Genipapo, enfatizando sua importância histórica, social e identitária para a cultura e a história local, bem como sua inserção dentro do contexto escolar da comunidade. Para tanto, retomamos os estudos de Morais Filho (1946), Querino (1914), Passarelli (2006) e Silva (2010). Quanto à metodologia, trata-se de uma abordagem qualitativa, pautada nos pressupostos teóricos da pesquisação. Nos instrumentos de obtenção e construção dos dados, realizamos uma revisão sistemática e de literatura, seguida de entrevistas semiestruturadas do tipo narrativa em oficinas pedagógico-culturais com sete professores/as. Esperamos com este estudo possibilitar um novo olhar acerca do percurso histórico do reisado, direcionando-o para as práticas educativas, transversalmente, a fim de responder a lacunas historicamente excludentes em relação à cultura popular e à história local, tendo em vista contribuir com o planejamento docente, desmitificando a visão urbanocêntrica de se pensar o currículo educacional que, atualmente, contribui para a descaracterização das tradições culturais locais, no sentido do distanciamento das suas peculiaridades, vivências, contexto histórico e sociocultural.
\end{abstract}

PALAVRAS-CHAVE: Reisado. Cultura popular. Processo histórico.

\begin{abstract}
This article presents the results of a research carried out at the State University of Bahia (UNEB), in the Professional Masters in Education and Diversity (MPED), in relation to the cultural tradition of the suit of figures and swords kings in the educational practices of the professors of Dom Antônio de Mendonça College, in Genipapo, Saúde BA. The study aimed to recall the historical process of the manifestation of Reisado, especially the suit of kings of figures and swords of the town of Genipapo, emphasizing its historical, social and identity importance for local culture and history, as well as their insertion within the community school context. For that, we return to the studies of Morais Filho (1946), Querino (1914), Passarelli (2006) and Silva (2010). As for the methodology, it is a qualitative approach, based on the theoretical presuppositions of the research. In the instruments for obtaining and constructing the data, we carried out a systematic and literature review, followed by semi-structured interviews of the narrative type in pedagogical-cultural workshops with seven teachers. We hope that this study will provide a new perspective on the history of reisado, directing it to educational practices, transversally, in order to respond to historically exclusive gaps in relation to popular culture and local history, with a view to contributing to the planning demystifying the urban-centered view of thinking about the educational curriculum, which currently contributes to the de-characterization of local cultural traditions, in the sense of distancing from its peculiarities, experiences, historical and sociocultural context.
\end{abstract}

KEYWORDS: Reissued. Popular culture. Historical process.

\footnotetext{
${ }^{1}$ Mestre em Educação e Diversidade pela Universidade do Estado da Bahia (UNEB). Professor da rede pública de ensino, poeta e cronista. Endereço eletrônico: afelopes@yahoo.com.br

2 Doutora em Letras pela Pontifícia Universidade Católica do Rio Grande do Sul (PUCRS). Professora Permanente do Mestrado em Educação e Diversidade pela Universidade do Estado da Bahia. Coautora e orientadora da pesquisa. Endereço eletrônico: dsousa@uneb.br
} 
Volume 13 - Número 1 - mai/jul de 2018

\section{Notas Introdutórias}

Este texto traz como objetivo principal rememorar o processo histórico da manifestação do reisado, especialmente, o terno de reis de figuras e espadas do povoado de Genipapo, em Saúde- BA, enfatizando sua importância histórica, social e identitária tanto para a cultura quanto para a história local, a fim de fortalecê-las, possibilitando sua inserção dentro do contexto escolar do Colégio Dom Antônio de Mendonça, em Genipapo, Saúde BA. Para tanto, retomamos os estudos de Morais Filho (1946), Querino (1914), Passarelli (2006) e Silva (2010). Quanto à metodologia, trata-se de uma abordagem qualitativa, pautada nos pressupostos teóricos da pesquisa ação. Nos instrumentos de obtenção e construção dos dados, realizamos uma revisão sistemática e de literatura, seguida de entrevistas semiestruturadas do tipo narrativa em oficinas pedagógico-culturais com sete professores/as.

Esperamos contribuir com a construção teórica acerca do percurso histórico do reisado, tendo um olhar direcionado para as práticas educativas no âmbito das escolas do campo $^{3}$, a fim de responder a lacunas historicamente excludentes em relação à cultura popular e à história local, visando desmitificar o olhar urbanocêntrico de se pensar o currículo educacional que, atualmente, contribui para o distanciamento das vivências e dos contextos histórico e sociocultural.

\section{Pra início de história...}

Destacamos algumas pesquisas que dialogam diretamente com o nosso objeto de estudo, com base numa revisão sistemática no banco de dados da Coordenação de Aperfeiçoamento de Pessoal de Nível Superior (CAPES), haja vista as contribuições de estudos teóricos na área do reisado e do terno de reis, tanto na Europa quanto no Brasil, desde o século XVIII, entre os quais citamos: Morais Filho (1946) e Querino (1914). E, mais recentemente, trabalhos de autores como: Passarelli (2006) e Silva (2010). A partir de suas pesquisas, constatamos o quanto são múltiplas as formas de rituais, festas e brincadeiras do reisado.

No que concerne às pesquisas da revisão sistemática sobre as temáticas cultura popular, terno de reis e práticas educativas, realizadas nos últimos dez anos, 7 (sete) trabalhos se destacam: o de Pires Neto (2005), Nascimento (2009), Chaves (2011), Silva (2011), Cornélio (2009), Corrêa (2013) e Silva (2014), os quais refletem acerca da cultura popular, ressaltando o papel desempenhado pelos folguedos, festas e rituais religiosos populares como elementos de afirmação de identidades locais, as construções simbólicas, históricas, sociais e culturais para a afirmação da tradição.

Para Silva (2008), nos ternos de reis, há uma poesia popular que reflete, através de seus cânticos religiosos, a perpetuação de uma série de crenças e valores sociais. Já, segundo Passarelli (2006), muitas são as divergências em torno dessa classificação, pois, para alguns, reisado só deve assim ser chamado apenas a manifestação que contenha este nome popular, strictu sensu, como no caso do reis de congo e reis de careta, excluindo-se, automaticamente, manifestações como as pastorinhas, folias, entre outros. Ainda, segundo Passarelli (2006, p. 78), “[...] para outros, o reisado está ligado às manifestações que apresentam cenas guerreiras

\footnotetext{
${ }^{3}$ Segundo Peripolli (2009), o campo é encarado como lugar de atraso, meio secundário e provisório. As políticas públicas de educação do Estado brasileiro são pensadas para suprir as demandas das cidades e das classes dominantes, geralmente instaladas nas áreas urbanas. Essas políticas têm se baseado em conceitos pedagógicos que colocam a educação do campo prioritariamente a serviço do desenvolvimento urbano-industrial. Na visão de educação do/no campo, considera-se e se respeita a existência de tempos e modos diferentes de ser, viver e produzir, contrariando a pretensa superioridade do urbano sobre o rural e admitindo variados modelos de organização da educação e da escola.
} 
ou àquelas que possuem um caráter mais reiseiro, laudatório". Pires Neto (2005) introduz uma reflexão sobre o modo abrangente e sistemático da cultura popular. Já Cornélio (2012) faz uma reflexão sobre a diversidade social das brincadeiras de Reis, sendo estas brincadeiras do período natalino, como música, canto, coreografia e poesia.

Chaves (2011) traz, na sua abordagem de pesquisa, a folia de reis como festa popular folclórica que, por meio da tradição e da memória oral, se mantém viva em seus costumes e crenças, revelando a identidade cultural de um povo. Silva (2011) busca compreender como se deram algumas das (re)significações simbólicas ocorridas no Reisado de Congo, do município de Barbalha, localizado no Cariri (sul) cearense, durante as décadas de 1960 e 1970. Apresenta um estudo dos sentidos e transformações das práticas culturais e de devoção presentes na história do terno dos Temerosos, na segunda metade do século XX, em JanuáriaMG. Machado (2010) considera a folia de reis um ritual cultural do folclore brasileiro, que tem sofrido mudanças significativas na atualidade. Esse estudo parte do pressuposto de que a valorização e preservação do patrimônio imaterial e material caracteriza-se como o próprio sentido da humanidade. Corrêa (2013), por sua vez, traz uma discussão sobre a folia de reis como manifestação popular que envolve música e devoção.

Por fim, Nascimento (2009), na sua dissertação de mestrado, intitulada E viva o santo reis: um estudo sobre manifestações culturais em Piatã/Abaíra, Chapada Diamantina, Bahia, demonstra o reisado como manifestação cultural da roça. Reporta-se ao domínio das práticas e representações do universo rural que se expressam nos ternos, buscando entendê-los a partir de uma perspectiva sócio-histórica e cultural, observando contribuições multiétnicas advindas do processo de colonização da Chapada Diamantina. Dentre os trabalhos já mencionados, este é o que mais se aproxima do nosso objeto de estudo, tendo em vista a busca por compreender a participação dos ternos de reis no âmbito da manifestação cultural da Chapada Diamantina, favorecendo o conhecimento desta prática cultural, em termos mais amplos e comparativos, e a relação estabelecida entre o reisado e o universo rural com o qual trava uma relação de interseção.

\section{Fé, cultura e tradição: o reisado chega ao Brasil Colonial}

Como constatamos nas mais diversas pesquisas, a folia de reis ou reisado é um auto popular que procura rememorar a trajetória dos Reis Magos, a partir do momento em que eles recebem o aviso do nascimento do Messias, até a hora em que encontram o Deus-menino. Essa expressão cultural tem origem portuguesa, chegando ao Brasil durante o período de colonização e incorporada ao folclore brasileiro, sendo comemorada em várias regiões do Brasil. Recorremos a Alencar ${ }^{4}$ (2011) que aborda, através de versos de cordel, como o reisado faz parte do imaginário popular nordestino:

Já se brincava a folia
No Brasil Colonial,
Vinte e quatro de dezembro
Meia-noite dá sinal,
Lá vem o Terno de Reis,
Que hoje é noite de Natal.
E até seis de janeiro,
Para os Magos festejar

\footnotetext{
${ }^{4}$ Nezite Alencar é uma historiadora nordestina e cordelista popular do Ceará. Possui vários livros publicados, os quais tratam de cultura popular no sertão cearense. Os versos aqui apresentados são do livro: Cordel das festas e danças populares, cujo título do cordel é Reisado ou Folia de Reis.
} 
Volume 13 - Número 1 - mai/jul de 2018

\section{$O$ reisado vai pra rua \\ De porta em porta a cantar: \\ "- Salve Gaspar, Melchior \\ E o santo rei Baltazar".}

Conforme a tradição católica, os Reis Magos foram visitar o menino Jesus levando presentes; porém, nos festejos folclóricos, eles nada levam, ao contrário, recebem dos donos das casas onde eles param e têm a permissão de entrar. Ao chegar às casas que os recebem, a primeira a entrar é a bandeira ou estandarte, que fica hasteada e todos, então, cantam a canção de chegada. Cada região brasileira insere elementos propícios à sua representatividade cultural. As cantigas, as danças, as vestimentas, e até mesmo as orações e as ladainhas envolvem a representação de uma determinada comunidade. Ainda, segundo Alencar (2011),

\author{
“- Acordai, ó boa gente, \\ Vinde ver a maravilha \\ Lá nas bandas do Oriente \\ Como um sol a estrela brilha \\ A caminho de Belém \\ Seguimos a mesma trilha". \\ Nos presentes do Menino \\ Nos ensina a Cristandade: \\ A realeza é o ouro, \\ No incenso a divindade, \\ Como nasceu nosso irmão, \\ Na mirra a humanidade. \\ Ao som de banjo e viola, \\ De pandeiro e maracá, \\ Um bando de mascarados \\ Dança pra lá e pra cá, \\ Vão proteger o Menino \\ Do "caipora" e "Jaraguá".
}

Percebemos através dos versos apresentados anteriormente que o terno de reis é um evento de cunho religioso e também cultural, uma tradição que remonta a uma história popular que reúne elementos das tradições orais, artísticas e culturais, misturando o sagrado da fé religiosa e o profano que amalgama o simbolismo de cada comunidade. A folia de reis também pode ser considerada um festejo, por isso, lúdico, uma vez que reúne elementos motivadores de ludicidade, cujos participantes ou os foliões, considerados brincantes, imergem na plenitude simbólica. E, Alencar (2011) continua cordelizando:

Vão defender o Menino

De Herodes, o rei malvado,

Os donos da estrebaria

Ficam um de cada lado,

São a burrinha e o boi

Que vêm dançar no reisado

Vêm a arara e a ema

Pra fazer estripulia,

$O$ "mestre" ou "embaixador" 
É quem puxa a cantoria,

Já o alferes carrega

A bandeira da folia.

Vão ao "rei" e à "rainha"

Que são o casal festeiro:

Meu senhor, dono da casa,

Estamos no seu terreiro

Para avisar que nasceu

Jesus, o Rei verdadeiro.

Rememorando o reisado e em consonância com Alencar (2011) e Silva (2008), as tradições populares do ciclo natalino eram comuns em toda a Europa Cristã, em países como França, Itália, Alemanha, Portugal e Espanha. Os dramas litúrgicos medievais eram utilizados como instrumento de ensino e divulgação da doutrina cristã. O episódio dos Magos do Oriente tornou-se um dos temas principais para efeito de dramatização. Representações de rituais litúrgicos relativos aos Magos que, a princípio, eram realizados no interior das igrejas, foram, pouco a pouco, popularizando-se e transportados para espaços abertos como praças e ruas. Assim surgiram os cortejos, vinculados aos templos religiosos das cidades, que encenavam a temática dos Magos, bem como grupos peditórios, no âmbito dos povoados rurais que, de casa em casa, levavam a mensagem do nascimento de Jesus Cristo.

No período colonial, os colonizadores, em conjunto com os missionários jesuítas que aportaram no Brasil, vindos com o primeiro governador geral Tomé de Sousa, em 1559 e em anos seguintes, trouxeram essas tradições da Península Ibérica. Estes utilizavam autos litúrgicos com a temática dos Reis Magos, sob a forma de canto, dança e encenação, no processo de catequese e ensino, tanto dos nativos indígenas como dos próprios colonos portugueses (reinóis) e, posteriormente, dos escravos negros. O catequista José de Anchieta, considerado por muitos um precursor das letras brasileiras, formado na escola de Gil Vicente, compôs, ensaiou e representou sua peça teatral inicial, Pregação Universal, reintitulada Na Festa de Natal, na Igreja dos Jesuítas, em São Paulo de Piratininga (atual cidade de São Paulo), no Natal de 1561, no Ano Novo e no dia de Reis de 1562 (SILVA, 2008).

Tudo indica que, no início da colonização, junto aos núcleos de povoamento mais consolidados (Salvador e vilas próximas do Recôncavo, Olinda e, pouco depois Recife, já sob o domínio holandês, Rio de Janeiro/Niterói e São Vicente/São Paulo de Piratininga), moldaram-se as formas iniciais das tradições das folias de Reis, no Brasil. Presépios, Lapinhas e Pastoris, seguindo-se de outras representações folclóricas derivadas, Reisados, Rancho de Reis, Terno de Reis (versão baiana), Guerreiros, etc.

Desta maneira, segundo Schechner (2012), os ternos de reis marcaram uma passagem no calendário social e religioso e, por isso, suas performances podem ser tomadas como uma espécie de ritual religioso advindo do paganismo, que foi absorvido pelo cristianismo e que se mantém vivo em Portugal e no sul do Brasil, onde houve forte influência portuguesa e açoriana. E, numa passagem do cântico a seguir, os brincantes do terno de reis, em Genipapo, de Saúde, deixam claro em sua apresentação performática esta influência direta dos portugueses:

\author{
Meu divino santo reis \\ Meu divino santo reis \\ Quando vinha de Lisboa \\ Quando vinha de Lisboa \\ Darindaré, darindaré, darindaré \\ Eu pedi sua palavra \\ Eu pedi sua palavra \\ Ele me deu a coroa \\ Ele me deu a coroa
}


Volume 13 - Número 1 - mai/jul de 2018

\author{
Darindaré, darindaré, darindaré \\ Ele me deu a coroa
}

O folclorista Manoel Querino, em 1916, em seu livro A Bahia de outrora, descreveu que numa noite de Reis na Bahia foi possível reconhecer a ocorrência de três tipos de agrupamentos festeiros: os ternos, os ranchos da burrinha e os ranchos do boi, localizando-os, respectivamente, na capital, em seus arrabaldes e no sertão baiano ${ }^{5}$. Não se referiu aos tipos raciais componentes desses grupos, mas à descrição feita das roupas usadas pelos pastores e pastoras, tanto quanto à menção dos instrumentos tocados pelas charangas que os acompanhavam, dados que coincidem, em sua maior parte, com a pesquisa de Morais Filho (1946).

Com a passagem do tempo, a maneira de realizar o reisado, assim como a data, foi variando de região para região do Brasil. Portanto, a origem do termo terno de reis, conforme a tradição, deve-se ao fato de que, como antigamente não havia rádio, nem internet, era preciso que as pessoas andassem pela comunidade anunciando acontecimentos, tais como: nascimento, casamento ou uma festa. E o dia de Reis era um desses dias festivos. Tinha que anunciar a chegada do "Salvador". E esse grupo passa então a receber a denominação de terno porque havia três vozes que, ao serem pronunciadas, poderiam ser ouvidas e propagadas o quanto mais longe possível: a primeira, a segunda e a oitava. A oitava, a voz agudíssima, bem alta, seria capaz de chegar ao infinito. Esta seria, então, a hipótese mais provável do surgimento da palavra terno para designar reisado ou folia de reis.

$\mathrm{Na}$ Bahia, as influências dos Autos Pastoris e das Janeiras se juntaram às contribuições indígenas e negras, resultando no Terno de Reis ou Ranchos de Reis, como era chamada a folia. No século XIX, os Ranchos de Reis são levados para o Rio de Janeiro, constituindo-se como um dos elementos para a criação das escolas de samba cariocas. A partir dessas informações, podemos observar que o reisado consiste em costumes legados pelo colonizador, que sofreram modificações e se reconfiguraram em virtude do processo de miscigenação (SILVA, 2008).

Num recorte mais proximal da nossa realidade, sabemos que a tradição do Terno de Reis está presente quase que totalmente em todo o interior baiano. Capital de forte crença católica, Salvador comemora o Terno na paróquia da Lapinha. Descrevendo, há cem anos, uma véspera de Reis na Bahia. Morais Filho (1946, p. 45) afirma que ali, "[...] os presepes, os bailes de pastoras e os descantes de Reis" se prolongavam "até o carnaval". E que "dessa noite em diante, os cantadores de Reis percorriam a cidade cantando versos de memória e de longa data" (MORAIS FILHO, 1946, p. 45). Sua descrição é rica em detalhes e inclui letras das cantigas entoadas pelos participantes dos ranchos, "[...] moças e rapazes de distinção, negros e pardos dirigiam-se ao presepe da Lapinha, às casas conhecidas em que se festejava o Natal ou tiravam Reis à aventura do acaso" (MORAIS FILHO, 1946, p. 46).

Historicamente, o folguedo do reisado foi introduzido em regiões da Bahia durante o processo de Entradas e Bandeiras das expedições portuguesas que buscavam ouro e pedras preciosas na Chapada Diamantina ${ }^{6}$. E, certamente, pela falta de comunicação e ausência de intercâmbio social e cultural, ele foi conservado em sua forma antiga naquelas zonas mais longínquas do interior da Bahia. Apresenta, inclusive, várias formas de enredo. $\mathrm{O}$ do município de Juazeiro é o que mais se assemelha ao saudense. Os praticantes do reisado personificam a história dos gladiadores romanos, dos três Reis Magos e a perseguição aos cristãos.

\footnotetext{
${ }^{5}$ Mencionar o Sertão Baiano tem um objetivo bem claro: dar visibilidade ao interior do Estado, especialmente ao Semiárido, Chapada Diamantina e Região de Irecê. Apesar da diversidade cultural e da importância política e econômica, o Sertão Baiano nunca teve a devida atenção por parte da grande mídia. As publicações de maior destaque nos veículos de comunicação, geralmente, possuem conotação negativa. Nossa proposta é colocar o Sertão Baiano no centro das atenções e demonstrar que nele existem fortes tradições culturais que têm contribuído de forma significativa com o desenvolvimento sociocultural da Bahia e do Brasil.

${ }^{6}$ A Chapada Diamantina é uma região de serra, protegida pelo Parque Nacional da Chapada Diamantina, situada no centro do estado brasileiro da Bahia, onde nascem quase todos os rios das bacias do Paraguaçu, do Jacuípe e do Rio de Contas.
} 
Volume 13 - Número 1 - mai/jul de 2018

\section{A cultura do reisado numa cidade do sertão da Bahia}

Como sabemos, a cultura do reisado sempre foi muito presente dentre as manifestações culturais nas cidades do sertão da Bahia, dentre elas ressaltamos o reisado intitulado Terno de Reis de Figuras e Espadas, do povoado de Genipapo, município de Saúde - BA, com base em entrevistas realizadas em fevereiro de 2018, com sete professores do Colégio Dom Antônio de Mendonça, durante a aplicação da I Oficina Pedagógico-Cultural (Identidade, Cultura e Ensino), a fim de rememorar e valorizar o terno de reis no âmbito escolar.

Quanto ao entendimento sobre o terno de reis, temos:

[...] surgiu de famílias tradicionais por volta de 1942. Apresentado por um senhor distinto chamado Silica, um ótimo tocador de viola e Domiciliano que comandou o terno de reis por muito tempo e seus companheiros foram Jerônimo, Otávio, Liberino. Domiciliano fazia o papel de cupido e as figuras que faziam coreografias eram Joaquina conhecida como (Tia Preta), Santinha, Alice e Agda. Na segunda formação de componentes composta tivemos: Chico Lopes, Leilson, Camilo, Nequinho e Benedito e as figuras eram Adelice, Zilda de Liberal, Raquel e Diná (GIRASSOL 1, 2018 ${ }^{7}$.

E, quando perguntados acerca de como e quando o terno de reis começou a se apresentar no município de Saúde, especificamente, no povoado de Genipapo, várias foram as declarações:

[...] há registros de 1964 que houve outro grupo bastante atuante com iniciativa de um senhor chamado Feliciano Araújo, que segundo o entrevistado, aquele senhor havia formado o terno com pessoas da sua própria família, e no momento ainda resta um membro que ainda faz parte, trata-se da senhora Helena Barrada sua nora". "São caracterizados com vestimentas azuis, brancas e vermelhas, sendo um lado azul e branco e outro vermelho e branco. Adornos e alguns usam espadas de madeiras e instrumentos musicais. Muitas pessoas a grande maioria tem o terno de reis como patrimônio cultural da comunidade (PINGO DE OURO, 2018).

[...] ocorreu em 1964, com o incentivo do velho que era meu sogro Domiciano Araújo, inclusive ele formou o terno de reis com pessoas da família dele e no momento só Helena G. Barradas faz parte. Para algumas pessoas o terno de reis significa a cultura do lugar e para outras significa uma simples diversão ou seja brincadeira. Usa viola, sanfona e pandeiro por que sem os instrumentos não tem animação (ROSA BRANCA 2018).

[...] os ternos são culturas, as pessoas se reúnem em grupos para as formas dos ternos de reis cada grupo tem seis componentes a partir da decisão começam a ensaiar para poder se apresentar no natal e seis de janeiro em comemoração do nascimento do menino Jesus e no dia seis de janeiro em comemoração aos reis magos. Surgiu a partir das famílias de Alexandre Almeida, Silica Araújo e Otávio. Antigamente, as pessoas tinham alegrias em receber o terno de reis mas hoje, tem pessoas que não quer que cante em sua casa pessoas daqui mesmo do povoado (GIRASSOL 2, 2018).

Fazendo um recorte mais específico acerca das tradições culturais locais, Silva (2008), ao tratar de educação e escola nas festas da cultura popular, recupera aquilo que se reflete,

\footnotetext{
${ }^{7}$ Por uma questão ética, os nomes dos colaboradores não serão identificados, assim, utilizaremos nomes de flores para nomeá-los, levando em consideração que a floricultura é a maior fonte de renda da comunidade saudense. Os nomes das flores foram escolhidos pelos colaboradores durante a I Oficina Pedagógico-Cultural, a saber: Girassol 1; Girassol 2; Pingo de ouro; Rosa branca; Gerbera; Veludo e Susci.
} 
Volume 13 - Número 1 - mai/jul de 2018

atualmente, como cultura popular e educação. Para isso, retoma valores profundos e fundamentais, que caracterizam a identidade de um povo, como vemos abaixo:

O terno de reis se apresenta no mês de dezembro e janeiro quando saem de casa em casa visitando as lapinhas, quando convidado também se apresenta e na semana que antecede dezembro e janeiro na festa de São Gonçalo de Amarante em Caém e nas escolas quando estas desenvolvem projetos de cultura e nas cidades vizinhas quando acontecem eventos culturais. O terno de reis são manifestações culturais que passaram de geração e geração e permanece até hoje em nossa comunidade. Desde quando comecei a ver a apresentação até hoje houve mudanças no vestuário e algumas músicas já não são mais cantadas e nem o bumba meu boi é morto e ressuscitado porque essa parte ninguém aprendeu para hoje apresentar e quem apresentava já morreu. (GIRASSOL 1,2018).

Nas narrativas, observamos, também, que o Terno de Reis de Figuras e Espadas do povoado de Genipapo, município de Saúde - BA, é típico de costumes de comunidades pequenas, de extrato bastante humilde, entre as classes ditas populares, termo que carece de discussão nos limites deste estudo. Surge esta iniciativa em comunidades de agricultores/as. Para essas pessoas, ditas 'do campo', o sentido de comunidade, bem comum, vizinhança e compadrio ainda é muito forte. Os elos que ligam vizinhos e compadres são vínculos extremamente estreitos, que motivam um ajudar o outro. Todos se ajudam mutuamente, todos se conhecem.

Assim, o nosso olhar sobre o cotidiano do povo simples e ordeiro do povoado de Genipapo, sua cultura, seus festejos e a harmonia entre as famílias. As festas de Natal, Ano Novo e Dia de Reis eram e ainda são um motivo a mais para reunir as famílias, os amigos, os vizinhos e compadres em torno de um sentimento de renovação e fraternidade, que ocorre de forma alegre, através do canto e da coreografia, como demonstra a letra de um dos cânticos do Terno de Reis ${ }^{8}$, fazendo uma alusão à vinda dessa manifestação de Portugal para o Brasil:

Meu divino Santo Reis
Meu divino santo reis
Meu divino santo reis
Com sua fita bonita
Com sua fita bonita
Darindaré, darindaré, darindaré
Com sua fita bonita
Eu pedi foi meia vara
Eu pedi foi meia vara
Ele me deu toda fita
Ele me deu toda fita
Meu divino santo reis
Meu divino santo reis
Com sua fita amarela
Com sua fita amarela
Darindaré, darindaré, darindaré
Com sua fita amarela...

Dessa forma, o Terno de Reis de Figuras e Espadas possui características que melhor se apresentam na atmosfera rural. Por sua atuação em lugares do interior, atualmente, ele se refaz,

\footnotetext{
${ }^{8}$ Os cânticos que seguem nas citações foram fotografados do livro de Cânticos de Reis datado de 1942. A cópia foi dedicada a umas das figuras do terno, cedida à professora colaboradora Magda Consuelo Barradas por uma

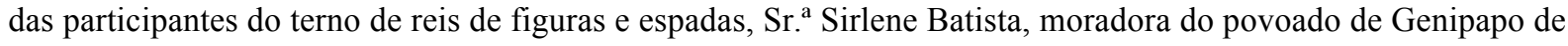
Saúde - BA.
} 
Volume 13 - Número 1 - mai/jul de 2018

incorporando mudanças que implicam na reconfiguração de novas identidades. Mudanças no modo de cantar, de realizar a apresentação, de se vestir.

Para Hall (2006), essa ação continua em virtude do refazer cultural, a partir das reconfigurações e hibridizações. Por se reconfigurar e hibridizar, o Terno de Reis não está posto no tempo como algo rígido e acabado; elementos novos de seu universo fazem com que novas gerações possam se identificar com a folia e assim ela seja passada de geração a geração. $\mathrm{O}$ estreitamento de laços e o sentido de comunhão e de pertencimento a uma família e à comunidade são as principais razões para a existência deste ritual, mas não as únicas. A união de forças entre vizinhos que vivem na mesma condição socioeconômica - bastante desfavorecida - explica muito do sentido do Terno de Reis em Genipapo. O cântico procura retratar como isso ocorre no cotidiano:

\author{
Quando eu cheguei nesta casa \\ Logo me cheirou a rosa \\ Meu coração bem me disse \\ Aqui tem gente formosa \\ Eu vou dá a despedida \\ A todos peço perdão \\ Para ir a outra parte \\ E cantar a oração \\ Eu por ser a mais pequena \\ Ficarei para o fim \\ Eu como não sei falar \\ Menino deus fala por mim \\ Os romeiros de Jesus \\ Quando tornaram descer \\ (Erguemos) \\ Entraram em sua casa.
}

No depoimento de Pingo de Ouro (2018), percebemos que tem havido um enfraquecimento dessas tradições: "Anteriormente as pessoas tinham satisfação em receber o terno de reis em suas casas. Hoje, a realidade é outra, o que enfraquece a cultura na localidade fazendo o grupo buscar outros horizontes". Já, no pensar de Girassol 1, o Terno de Reis tem valor cultural bastante significativo para muitas pessoas da localidade de Genipapo:

Existe a necessidade desse sentimento ser perpassado para a
comunidade escolar de maneira que essa transmissão de valores e de
conhecimento seja passada de forma prazerosa buscando conhecer mais
suas origens, suas vivências no espaço de tempo para que de fato todos
possam ter um olhar mais respeitoso com valorização de sua própria
cultura. (GIRASSOL 1,2018)

A outra explicação subjacente é a perpetuação do núcleo familiar como célula social, pois as visitas aconteciam em casas de famílias, feitas para as famílias da comunidade e o Terno de Reis, muitas vezes, congregava famílias inteiras na cantoria. Assim, a apresentação praticada no terno de reis tinha a função de agregar a sociedade e as famílias, manter o tecido social coeso e unido em prol do bem da comunidade a que pertencia. Daí a sua perpetuação desde tempos imemoriais até os dias de hoje, como é narrado a seguir o universo que se inseriam os brincantes do Terno de Reis e de Figuras e Espadas, de Genipapo. O cântico abaixo traduz-se como uma 
Volume 13 - Número 1 - mai/jul de 2018

demonstração de como a comunidade participa do terno de reis, resguardando as suas antigas tradições. Ei-los:

\author{
Vos nos dai festa feliz \\ Estimado morador \\ A bênção de deus nos cubra \\ De bênção e favor
}

Deixamos nossa morada

Marchemos alegremente

Vamos visitar Jesus

Que é o rei do oriente

Senhor dono da casa

Que quer que seja que é

Com cravo de almirante

Com a sucena no pé

Eu vim aqui nessa casa

Saudoso hino cantar

Sua voz amasiosa

Até o céu agradar.

Eis de ouvir sempre cantiga

De gracioso camponês

As aldeias conduzidas

Cordeiro e mansos reis

Neste entendimento, o Terno de Reis, de Genipapo, é uma manifestação cultural do homem do campo em virtude das observações presentes no cotidiano das comunidades rurais. Para Silva $(2008$, p. 232), “[...] as festas populares do campo são imagens do que mulheres e homens fazem juntos quando se reúnem, numa quebra do cotidiano, para compartir algo, para conviver, rememorar, celebrar, festejar, honrar um deus, um santo ou alguma pessoa, enfim, comemorar algo: 'festar'." E, tais costumes, por um longo período, permaneceram no universo popular europeu, chegando ao Brasil por obra dos primeiros colonizadores. Embora existam essas apresentações pontuais, há uma tentativa de rememorar o reisado com formas e conteúdos da cultura popular da comunidade. Outrossim, é urgente que haja a inserção destas tradições nas práticas escolares, agregando aos currículos escolares esses saberes que fazem e perfizeram o cotidiano da comunidade através dos tempos.

Vale ressaltar que o Terno de Reis de Figuras e Espadas, de Genipapo, em Saúde- BA, possui caráter dinâmico, ao mesmo tempo que enraiza em cada membro do grupo social seus valores, suas normas e suas tradições. A cada geração, abrem-se espaços para novas maneiras de representar, conservar e aliar à prática a reposição do perdido ou de transformação daquilo que se mantém. Conforme Silva (2008, p.133),

[...] por se tratar de uma enorme família, é bem e representativo o número de crianças que participam desses grupos, o que estimula e desenvolve o seu lado lúdico, fazendo-se interagir internamente, acelerando o processo de ensino-aprendizagem, inerente ao meio acadêmico (escolas) - primeiro contato com educação patrimonial. Essa experiência e a aproximação dos mais jovens são fundamentais para a perpetuação dessas tradições, uma vez que os detentores do "conhecimento" encontram-se em sua maioria, com idade avançada e, em alguns casos, infelizmente, não podem mais difundir seu rico legado. Vivenciando $o$ fato folclórico, as crianças 
Volume 13 - Número 1 - mai/jul de 2018

conhecem/absorvem melhor esse conhecimento transmitido pelos mestres, reforçando seus laços culturais e conscientizando-se de sua identidade.

A escola é, portanto, o ambiente propício para a aprendizagem do respeito pelas culturas populares, pouco divulgadas na televisão (portanto diferentes daquilo que se tornou normal para os jovens), obtido a partir do conhecimento de suas formas de expressão materiais e imateriais, na complexidade de suas dimensões históricas, geográficas, sociais, artísticas e religiosas. Só assim a cultura popular poderá ser reconhecida e respeitada, visando alcançar a legitimidade de que hoje goza a cultura erudita, na escola ou fora dela. E abrindo caminho para que, um dia, o mestre-popular se torne mestre-escola.

\section{Avante o santo reis...}

Consideramos, então, que a socialização de estudos, nesta temática, é também papel das universidades, quando se concebe estas manifestações culturais locais e a escola como um lugar privilegiado à construção de conhecimentos. Outrossim, é urgente que haja a inserção destas tradições nas práticas escolares, agregando aos currículos escolares estes saberes que fazem e perfazem o cotidiano das comunidades através dos tempos. Torna-se um imperativo cada vez maior nos meios educacionais brasileiros, em face das políticas de valorização da diversidade cultural, a inclusão de conteúdos sobre culturas populares tradicionais como temas curriculares transversais. Nesse contexto, vemos a necessidade de preencher uma grande lacuna, ao oferecer informações pedagogicamente organizadas sobre as expressões da cultura popular, as quais integram uma importante parcela do conhecimento humano, que vem sendo apartado dos currículos escolares. Assumindo nosso compromisso de educadores e de formadores de educadores, desafiamo-nos a desenvolver este estudo investigativo com o objetivo de contribuir para a difusão do conhecimento sobre esses discursos sociais e os sujeitos discursivos implicados.

\section{REFERÊNCIAS}

ALENCAR, Nezite. Cordel das festas e danças populares. São Paulo: Paulus, 2011. CHAVES, Danisa. Folia de reis na cidade de Três Corações: um estudo sobre cultura popular na Festa de Reis. 2011. 76f. Dissertação (Mestrado em Letras) - Universidade Vale do Rio Verde- UNICOR- Três Corações- MG, 2011.

CORRÊA, Jussânia Borges. “Aprendê de cabeça": a viola caipira nas Folias de Reis. 2013. $91 \mathrm{f}$. Monografia (Licenciatura em Música) - Universidade de Brasília, Brasília, 2013.

CORNELIO, Paloma Sá de Castro. REISADO CARETA: play to praise Santo Reis. 2009.

81 f. Dissertação (Mestrado em Sociologia e Antropologia) - Universidade Federal do Maranhão, São Luis, 2009.

HALL, Stuart. Da diáspora - identidades e mediações culturais. Belo Horizonte: Editora UFMG, 2006

MACHADO, Cláudia Carvalho. The folia de Santos Reis: values and conservation of manners. 2010. 153f. Dissertação (Mestrado em Ciências Humanas) - Pontifícia Universidade Católica de Goiás, Goiânia - GO, 2010.

MORAIS FILHO, Melo. A véspera de Reis (Bahia). In: populares do Brasil. 3. ed. Rio de Janeiro: F. Briguiet\& Cia., 1946.

NASCIMENTO, Ildimar França. E viva Santo Reis: um estudo sobre manifestações culturais em Piatã/Abaíra, Chapada Diamantina, Bahia. Salvador, 2009.

PASSARELLI, Ulisses. Tipologia dos reisados brasileiros: estudo preliminar. Natal, 2006. Disponível em: <http:// www.csr.xpg.com.br/tipologia.doc >. Acesso em: 22 abr. 2017. 
PERIPOLLI, Odimar João. Expansão do capitalismo na Amazônia norte matogrossense: a mercantilização da terra e da escola. 2008. 267f. Tese (Doutorado) - UFRGS, Porto Alegre/RS, 2009.

PIRES NETO, Josias. Bahia singular e plural. Registro audiovisual de folguedos, festas e rituais populares. Salvador. Secretaria de Cultura e Turismo: Fundação Cultural, 2005.

QUERINO, Manuel Raymundo. A Bahia de outrora - vultos e fatos populares. Salvador Bahia. Econômica, 1916.

SCHECHNER, Richard. Antropologia e performance. São Paulo: Hucitec, 2012.

SILVA, René Marc da Costa (Org.). Cultura popular e educação. Brasília: MEC, Secretaria de Educação à distância, 2008.

SILVA, Simone Pereira da. Os sentidos da festa: (re)significações simbólicas dos brincantes do Reisado de Congo em Barbalha CE (1960-1970). 2011. 143 f. Dissertação (Mestrado em História) - Universidade Federal da Paraíba, João Pessoa, 2011.

SILVA, Johnisson Xavier. O terno dos temerosos: as transformações e sentidos de suas práticas culturais na segunda metade do século XX. 2014. 155 f. Dissertação (Mestrado em Ciências Humanas) - Universidade Federal de Uberlândia, Uberlândia, 2014. 